\title{
EL MODELO DE INVESTIGACIÓN EN BIOÉTICA ${ }^{1}$
}

\author{
Oscar J. Martínez González \\ Facultad de Bioética, Universidad Anáhuac
}

\section{Conceptos generales}

Cada forma del saber se constituye a través de una metodología que es fruto de la misma madurez epistemológica de la disciplina. En toda investigación, el método es dictado por la finalidad que se pretende alcanzar y en bioética debería asumir el método específico de la reflexión ética.

Por otra parte, no debemos olvidar que la bioética es el área del conocimiento que se instala en una dimensión interdisciplinaria que, en muchas ocasiones, confunde su verdadera finalidad: ayudar en la reflexión de los conceptos éticos que inciden en la práctica de las ciencias de la salud.

La presencia de una gran cantidad de principios en bioética que luego son traducidos como derechos hace difícil la argumentación ética. Muchas veces, en lugar de buscar una jerarquía de valores, lo que parece que se pretende encontrar es cuál principio es más principio que el resto.

La investigación en bioética necesita revisar y valorar procesos y acciones mediados por el conocimiento científico y tecnológico. Cuando se valoran situaciones particulares en bioética, es necesario establecer una jerarquía no arbitraria de bienes para tutelar en cada situación singular.

\section{Propuesta}

En primer lugar, en bioética se debería presentar el hecho biomédico, comprobando científicamente su consistencia y exactitud. En segundo término, se debería profundizar en su significado antropológico para ir, en tercer lugar, a la identificación de los valores en el juego ${ }^{2}$.

Esta metodología permite, en un primer momento, la clarificación del tema (momento descriptivo) $\mathrm{y}$, en un segundo, la presentación de conclusiones

1 Tomado en parte de Pessina A. La cuestión del método en la perspectiva de la bioética de visión personalista. Medicina y Ética 2005; 16(3): 255-266.

2 Sgreccia E. Manual de Bioética. México: Diana; 1996. (momento prescriptivo), discutiendo las perspectivas metaempíricas presentes.

El concepto ético y antropológico de la bioética personalista es de tipo cognitivista, es decir, se mueve en la convicción de que se pueden alcanzar algunas verdades en torno al hombre, reconocibles en principio por todos.

Si la imagen del ser humano y de su existencia fuera solamente el fruto histórico y cultural de las opciones del individuo singular y de la comunidad, no se comprende qué se debería pretender en las confrontaciones de la actividad médica y científica como el único criterio de lo verdadero y de lo falso.

Si la ética no pudiera decir nada sensato, nada verdadero o falso, entonces debería dejarse a la ciencia la tarea de establecer qué debe hacerse. Pero la respuesta científica a esta pregunta no puede ser sino sólo una respuesta fáctica.

La bioética no está pensada como una suma de competencias de conocimiento. Emerge como una interdisciplina, constituida a través de un camino que tiene éxito donde se ha formado juicio de conciencia, basado en verdades adquiridas e integradas, y en diversos bienes puestos en juego.

Este método se distingue del que otros proponen, tanto por su connotación de contenido, como por su estructura crítica. La bioética no puede limitarse a la clarificación de los valores en juego, confiando la solución de los eventuales dilemas prácticos a la elección de los agentes morales individuales, sino que debe, a través de la descripción y comprensión de los datos que se relacionan con el problema, aportar soluciones, haciendo referencia a contenidos éticos precisos.

El momento prescriptivo no es fruto de una deducción pura de los principios morales, sino que surge dentro de un complejo itinerario teórico que tiene en cuenta diversas aproximaciones a la realidad, y que hace posible la actividad cognoscitiva del hombre. Esta referencia a la praxis cognoscitiva 
que comunica estas disciplinas es el fundamento de legitimidad de la valoración ética, tiene siempre como objeto los actos humanos e interviene para identificar los bienes en juego.

El carácter dinámico de este proceso nos permite recordar su alcance dialéctico: la misma verdad sobre el hombre, en sus múltiples dimensiones, es una ganancia teorética y no sólo una herencia del pensamiento clásico. Desde esta perspectiva, se comprende el esfuerzo por encontrar las razones que hacen de la antropología y de la ética saberes que se alcanzan discutiendo y argumentando, tomando en serio las tesis que se contraponen a este itinerario.
Es propio de la estructura dialéctica y argumentativa de la razón, la capacidad de considerar todo aquello que se le presenta como contribución al descubrimiento de la verdad. Esta capacidad metodológica de no excluir a priori a ningún interlocutor y de saber distinguir la fuente de una tesis de su valor en sí permite proporcionar una indicación precisa dentro del pluralismo ético actual.

Cuando se actúa en nombre de la moral se actúa en nombre de la humanidad y, por ello, se interpela a cada hombre como sujeto moral. De ahí deriva el impulso de confrontar y discutir en la búsqueda de la verdad y no exigir el dominio ni del consenso. 